\title{
Smokers with airway obstruction are more likely to quit smoking
}

\author{
M Bednarek, D Gorecka, J Wielgomas, M Czajkowska-Malinowska, J Regula, \\ G Mieszko-Filipczyk, M Jasionowicz, R Bijata-Bronisz, M Lempicka-Jastrzebska, \\ M Czajkowski, G Przybylski, J Zielinski
}

See end of article for authors' affiliations .....................

Correspondence to: Professor J Zielinski, National Research Institute of Tuberculosis and Lung Diseases, 2nd Department of Respiratory Medicine, 26 Plocka Street, 01-138 Warsaw, Poland;

j.zielinski@igichp.edu.pl

Received 15 January 2006 Accepted 6 June 2006 Published Online First 29 June 2006
Background: Chronic obstructive pulmonary disease (COPD), usually caused by tobacco smoking, is one of the leading causes of morbidity and mortality. Smoking cessation at an early stage of the disease usually stops further progression. A study was undertaken to determine if diagnosis of airway obstruction was associated with subsequent success in smoking cessation, as advised by a physician.

Methods: 4494 current smokers $(57.4 \%$ men) with a history of at least 10 pack-years of smoking were recruited from 100000 subjects screened by spirometric testing for signs of airway obstruction. At the time of screening all received simple smoking cessation advice. 1177 (26.2\%) subjects had airway obstruction and were told that they had COPD and that smoking cessation would halt rapid progression of their lung disease. No pharmacological treatment was proposed. After 1 year all subjects were invited for a follow up visit. Smoking status was assessed by history and validated by exhaled carbon monoxide level.

Results: Nearly 70\% attended a follow up visit $(n=3077)$ : $61 \%$ were men, mean (SD) age was 52 (10) years, mean (SD) tobacco exposure 30 (17) pack-years, and 33.3\% had airway obstruction during the baseline examination. The validated smoking cessation rate in those with airway obstruction was $16.3 \%$ compared with $12.0 \%$ in those with normal spirometric parameters $(p=0.0003)$. After correction for age, sex, nicotine dependence, number of cigarettes smoked daily, and lung function, success in smoking cessation was predicted by lower lung function, lower nicotine dependence, and lower tobacco exposure.

Conclusions: Simple smoking cessation advice combined with spirometric testing resulted in good 1 year cessation rates, especially in subjects with airway obstruction.
C hronic obstructive pulmonary disease (COPD) is one of the leading causes of morbidity and mortality worldwide and is increasing in prevalence. ${ }^{1}$ In the United States, between 1966 and 1995 age adjusted death rate for stroke and coronary artery disease declined by $58 \%$ and $45 \%$ respectively, ${ }^{2}$ whereas the death rate from COPD increased by $71 \%^{1}$ making it the fourth leading cause of death. Direct annual costs for COPD in the US were estimated to be over $\$ 18$ billion, ${ }^{3}$ and the economic impact of work loss accounted for an additional $\$ 10$ billion. ${ }^{4}$ The morbidity and mortality from cardiovascular diseases have been successfully reduced over the last 40 years as a result of effective preventive measures. However, the concurrent failure of pharmacological treatment to affect the increasing death rates from COPD should encourage new methods to be sought to reverse this trend. ${ }^{5}$

Tobacco smoke is the main cause of COPD, responsible for $85-90 \%$ of all cases. ${ }^{67}$ Smoking cessation at an early stage of the disease has been proved to slow down the decline in forced expiratory volume in 1 second $\left(\mathrm{FEV}_{1}\right)$ to that observed in healthy subjects. ${ }^{89}$ The diagnosis of COPD at an early stage of the disease may be done by performing spirometric tests in smokers using case finding ${ }^{10}$ or population screening ${ }^{11}$ methods. We hypothesised that the diagnosis of smoking related lung disease would increase the efficacy of smoking cessation advice in affected subjects. The aim of this study was to compare the effects of spirometric tests combined with simple smoking cessation advice on rates of smoking cessation in two groups of subjects-those with airway obstruction and those with normal spirometric parameters.

\section{METHODS}

Investigations were performed as part of the National Program of Early Diagnosis and Prevention of COPD in Poland. ${ }^{11}$ The National Program was introduced to promote early diagnosis and secondary prevention of COPD. Written materials were disseminated for local TV, radio and journals. Special posters and leaflets were displayed in healthcare facilities. Materials included information on causes and symptoms of COPD. In some places it was felt that the term "COPD" was unfamiliar and was replaced by a better known term "emphysema". Information that not all smokers are susceptible to COPD and that a spirometric test is a simple non-invasive method to detect COPD at an early stage of the disease were also included. Smokers aged $40+$ years with a history of at least 10 pack-years were invited to outpatient chest clinics all over the country for a free breathing test. However, all subjects who visited the clinic for spirometric tests-whether younger than 40 years of age or nonsmokers-were also accepted. All investigated subjects were volunteers responding to the offer of free spirometric tests and smoking cessation counselling. No patients with chronic chest diseases were included in the study. Screening clinics were held on Saturday mornings and during the late afternoon on working days, facilitating fully employed subjects to attend the test. Outpatient chest clinics are usually located in a town centre with easy access to public transportation.

Abbreviations: $\mathrm{CO}$, carbon monoxide; COPD, chronic obstructive pulmonary disease; $\mathrm{FEV}_{1}$, forced expiratory volume in 1 second; FTND, Fagerström test for nicotine dependence; FVC, forced vital capacity 


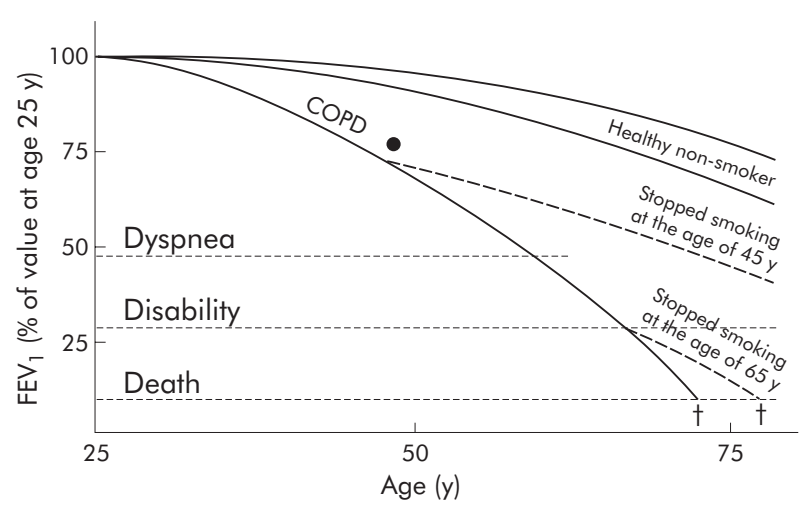

Figure 1 Fletcher and Peto ${ }^{15}$ diagram discussed with participants who had airway obstruction. A black dot was placed at the intersection of the participant's $\mathrm{FEV}_{1} \%$ predicted and current age.

Simple spirometric tests with measurements of forced vital capacity (FVC) and $\mathrm{FEV}_{1}$ were performed by registered nurses trained in spirometric testing at the lung function laboratory of a chest hospital. Training was completed with an examination and certificate. A few of the technologists attended a high school for medical technicians where spirometric testing is part of the curriculum. Spirometric tests were performed in accordance with American Thoracic Society guidelines. ${ }^{12}$ Predicted spirometric values of ECCS/ ERS were used. ${ }^{13}$ Following the 1995 ERS guidelines, ${ }^{14}$ the presence of airway obstruction was defined as an $\mathrm{FEV}_{1} / \mathrm{FVC}$ $<88 \%$ predicted, and the severity of the impairment was classified using $\mathrm{FEV}_{1}$ percentage predicted as follows: $>70 \%$ mild, 50-69\% moderate, $<50 \%$ severe.

The physician in charge of the National Program discussed the results of the spirometric tests with each subject, relating the results to his/her smoking habit. The subject's percentage predicted $\mathrm{FEV}_{\mathrm{l}}$ value was superimposed on a simplified Fletcher's diagram, ${ }^{15}$ showing the relationship of the actual result with the predicted value for age and the expected subsequent $\mathrm{FEV}_{1}$ decline in future if the subject continued to smoke (fig 1). All participants were strongly encouraged to stop smoking and received a smoking cessation booklet to take home. This booklet provided information on the harmful effects of tobacco smoke, the positive health and economic effects of smoking cessation, and useful hints on how to stop smoking. Smoking cessation advice and discussion on the breathing test result took an average of 5-7 minutes. No pharmacological treatment of smoking addiction was offered. Nicotine replacement therapy was available over the counter in Poland at the time of this project; however, nicotine replacement gum, patches and inhalers are not reimbursed and are rather expensive. In subjects with normal spirometric parameters, smoking cessation advice was focused on the risk of developing COPD, lung cancer, coronary artery disease, and the harmful effects of smoke to family members. Fletcher's diagram was also shown.

A total of 110000 subjects were screened in the Program. ${ }^{11}$ Ten of the 60 chest clinics taking part in the Program with the highest number of subjects enrolled in different regions of the country were chosen to assess the effects of the smoking cessation advice 1 year after the initial visit. Subjects screened at centres selected for the study did not differ from those in the remaining centres in terms of sex $(58.6 \% v 58.0 \%$ male), nicotine dependence (4.73 v 4.76 Fagerström Test for Nicotine Dependence (FTND) points), and severity of airflow limitation $\left(\mathrm{FEV}_{1} \%\right.$ predicted 89.95 (23.5) v 86.79 (27.4)). There was a statistically significant difference between subjects in the selected and the remaining centres in age (54.2 (12.3) v 53.3 (11.3) years), age at smoking initiation
(19.9 (5.0) v 20.3 (5.2) years), number of cigarettes smoked daily (19.5 (9.9) v $18.9(9.4)$ ), and cumulative exposure to tobacco smoke (30.1 (19.3) v 28.7 (18.7) pack-years), respectively. However, because of the very large number of subjects included $(\mathrm{n}=110000)$, these differences were not considered clinically significant.

During the years 2000-2001, 4494 current smoking adults attended the Program at the clinics chosen: 2580 men $(57.4 \%)$ and 1914 women $(42.6 \%)$. From this group, $26.2 \%$ were found to have airway obstruction: $7.5 \%$ mild, $13.5 \%$ moderate, and $5.2 \%$ severe. The remaining $73.8 \%$ either had normal spirometric parameters or mild reductions in FVC without airway obstruction.

A letter of invitation for a follow up visit was mailed to all subjects of the group during the 1lth month following the initial visit. In five centres the letter of invitation was resent after 1 month if the invited person had not responded. Some of the subjects $(13.2 \%)$ were invited for follow up by a telephone call. In one centre a telephone call was also repeated after 2-4 weeks if the subject did not respond to the first call.

During the follow up visit, subjects completed a standardised questionnaire including questions on current smoking status, number of cigarettes smoked, motivation to stop smoking, and Fagerström Test for Nicotine Dependence (FTND). ${ }^{16}$ Those who declared complete abstention from smoking for 1 year were called sustained quitters. Selfreported non-smoking status was validated by an exhaled carbon monoxide (CO) level of less than 10 ppm (Micro CO, Micro Medical Ltd, Rochester, UK).

\section{Statistical analysis}

Statistical analyses were performed using Statistica version 6.0 software (StatSoft Inc, Tulsa, Oklahoma, USA). Tests were considered significant when $\mathrm{p}<0.05$. Data distribution was analysed using the Kologomorov-Smirnov test with Lilliefors correction. Quantitative data were described using mean (SD) values. Between group characteristics were described using analysis of variance. Homogeneity of variance was assessed using Levene's test. If a variable demonstrated normal distribution and homogeneous variance, the F ANOVA test was applied. Otherwise, a nonparametric Kruskal-Wallis H test was used. To characterise the strength of the relationships between continuous variables, Pearson correlations were used. Categorised qualitative between group analyses were performed using a Pearson $\chi^{2}$ test with appropriate corrections for $\mathrm{N}$. To assess the influence of confounding categorised and continuous variables on smoking cessation rate after l year, a logistic regression model was used. Odds ratios (OR), confidence intervals (CI) and p values were calculated.

\section{RESULTS}

A total of 3077 subjects, representing $68.5 \%$ of those invited, attended a follow up visit: 1867 men and 1210 women. At the baseline examination one third $(n=1026)$ had airway obstruction which was mild in $271(8.8 \%)$, moderate in 545 $(17.7 \%)$, and severe in $210(6.8 \%)$. There were no statistically significant differences in the smoking history, age, or sex of those who attended the follow up visit and those who did not (non-responders). However, smokers with airway obstruction were more likely to attend a follow up visit (87.2\%) than smokers with normal spirometric parameters (61.6\%, $\mathrm{p}<0.001)$. The follow up response rate also differed slightly according to the severity of airway obstruction: $80.4 \%$ with mild obstruction, $89.9 \%$ with moderate obstruction, and $89.7 \%$ with severe obstruction $(\mathrm{p}=0.025)$.

The mean (SD) age of the 3077 subjects was 52.1 (10.5) years and the mean (SD) smoking exposure was 
Table 1 Baseline characteristics, smoking status, and lung function stratified by sex and spirometric results

\begin{tabular}{|c|c|c|c|c|c|}
\hline \multirow[b]{2}{*}{ Variable } & \multirow[b]{2}{*}{ Total } & \multicolumn{2}{|c|}{ Normal spirometry } & \multicolumn{2}{|c|}{ Airway obstruction } \\
\hline & & Men & Women & Men & Women \\
\hline$N(\%)$ & 3077 (100\%) & $1192(38.7 \%)$ & $859(27.9 \%)$ & $675(21.9 \%)$ & $351(11.4 \%)$ \\
\hline Age (years) & $52.1(10.5)$ & $50.1(11.1)$ & $50.0(8.9)$ & $56.8(9.9)$ & $55.0(9.6)$ \\
\hline Age of smoking initiation (years) & $19.8(4.9)$ & $18.9(4.4)$ & $21.1(5.1)$ & $18.7(4.0)$ & $21.6(5.9)$ \\
\hline Cigarettes per day & $18.9(8.3)$ & $19.8(8.7)$ & $16.9(6.9)$ & $20.0(8.8)$ & $18.8(7.9)$ \\
\hline Pack-years & $30.0(17.0)$ & $30.4(17.2)$ & $23.9(12.5)$ & $37.0(16.6)$ & $31.0(15.6)$ \\
\hline $\mathrm{FEV}_{1} / \mathrm{FVC}(\%)$ & $74.2(12.9)$ & $81.1(7.4)$ & $81.9(7.3)$ & $59.2(9.3)$ & $60.1(7.5)$ \\
\hline $\mathrm{FEV}_{1}$ (I) & $2.70(0.9)$ & $3.46(0.8)$ & $2.45(0.5)$ & $2.2(0.8)$ & $1.69(0.6)$ \\
\hline $\mathrm{FEV}_{1}(\%$ predicted) & $88.5(22.8)$ & $97.2(17.8)$ & 96.5 (17.5) & $66.1(20.2)$ & $69.0(19.9)$ \\
\hline FTND (points) & $4.76(2.5)$ & $4.85(2.4)$ & $4.44(2.5)$ & $4.93(2.4)$ & $4.99(2.4)$ \\
\hline No. of previous cessation attempts & $1.69(3.5)$ & $1.78(4.4)$ & $1.80(3.0)$ & $1.47(2.5)$ & $1.37(2.1)$ \\
\hline
\end{tabular}

Values are mean (SD) unless otherwise indicated.

$\mathrm{FEV}_{1}$, forced expiratory volume in 1 second; FVC, forced vital capacity; FTND, Fagerström test for nicotine dependence.

30.0 (17.0) pack-years. The mean FTND score was 4.76 (2.4) points. Descriptive statistics categorised according to spirometric results and sex are shown in table 1.

Successful smoking cessation during the 1 year follow up visit was confirmed by a low exhaled CO level in 686 subjects. Mean (SD) exhaled CO in sustained quitters was 5.01 (3.4) ppm compared with 17.2 (7.7) ppm in subjects continuing to smoke $(\mathrm{p}<0.001)$. Subjects who continued to smoke reported a lower mean number of cigarettes smoked per day: 19.5 (8.2) at baseline and $16.5(8.1)$ at 1 year follow up. The cessation rates were $23.3 \%$ for men and $20.8 \%$ for women $(p=0.11)$. Smokers with airway obstruction were more likely to have quit smoking $(26.6 \%)$ than those with normal spirometry $(20.1 \%, \mathrm{p}<0.001)$.

The smoking cessation rate was recalculated using the conservative assumption that all subjects who did not come for the follow up visit were continuing smokers. The overall recalculated smoking cessation rate was $13.4 \%$ (14.6\% in men and $11.7 \%$ in women), and this difference was statistically significant $(p=0.01)$. The smoking cessation rate in those with airway obstruction remained higher than in subjects with normal spirometric parameters (16.3\% v $12.0 \%$, $\mathrm{p}=0.0003$ ).

Independent predictors of successful smoking cessation included older age, older age at onset of smoking, fewer cigarettes per day, lower cumulative tobacco exposure, a lower FTND score, and lower spirometric values (table 2). Subjects with moderate and severe airway obstruction were more likely to quit (table 3 ).

Although airway obstruction was a strong predictor of success in stopping smoking, other confounding variables could play a role. To assess possible relationships, a logistic regression analysis was used, adjusting the model for sex, age, number of cigarettes smoked daily, nicotine dependence
(FTND), and airway obstruction (table 4). The logistic regression model showed significant effects of nicotine dependence, number of cigarettes smoked daily, and airflow obstruction as predictors of smoking cessation. The effect of impaired lung function was the strongest predictor of sustained cessation (OR 1.6).

\section{DISCUSSION}

Spirometric testing combined with simple short smoking cessation behavioural support resulted in a $12 \%$ sustained (12 month) smoking cessation rate in smokers with normal spirometric parameters and a $16.3 \%$ rate in smokers with airway obstruction. These rates exceed the $4-6 \%$ cessation rates reported after physician advice. ${ }^{17-19}$ In Poland in 2005, a smoking cessation initiative called "The Great Polish Smokeout" covered around 10 million smokers. After the action, 100000 smokers (1\%) declared that they had quit smoking, another $600000(6 \%)$ tried to stop smoking temporarily, and $1400000(14 \%)$ reduced the number of cigarettes smoked daily. These unpublished data reflect the spontaneous cessation rates after repeated smoking cessation appeals in the mass media, on billboard and pickets.

Better sustained cessation rates were reported in smokers with diseases related to or aggravated by smoking. In a large controlled British Thoracic Society (BTS) study in 1550 subjects, at the end of 1 year $9.7 \%$ had successfully stopped smoking. Smoking cessation was verified by carboxyhaemoglobin and thiocyanate measurements. ${ }^{20}$ In our study the smoking cessation rate in men was higher than in women $(14.6 \% v 11.7 \%)$. The difference between the sexes was much lower than that observed in the BTS study where sustained smoking cessation rate in men more than doubled the cessation rate in women $(12.2 \% v 5.3 \%) .{ }^{21}$

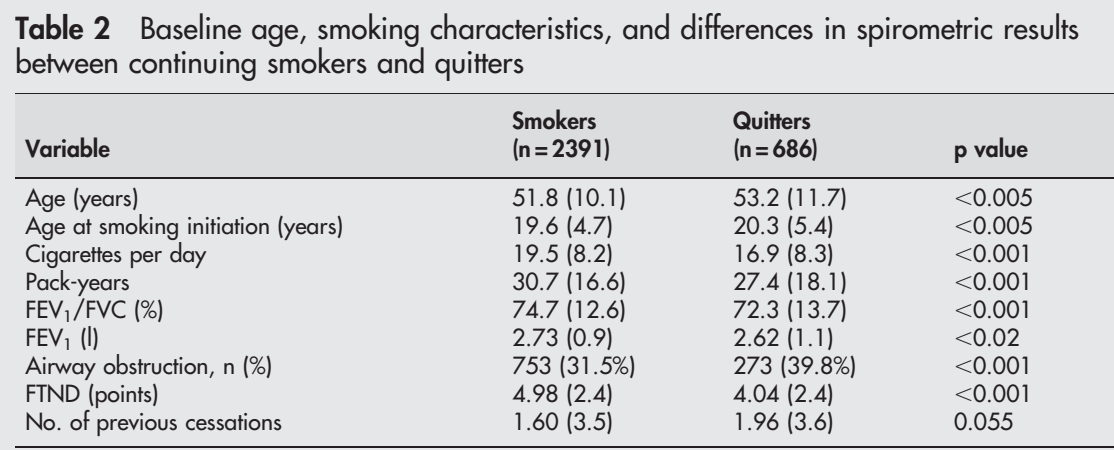

Values are mean (SD) unless otherwise indicated. $\mathrm{FEV}_{1}$, forced expiratory volume in 1 second; FVC, forced vital capacity; FTND, Fagerström test for nicotine dependence. 
Table 3 Smoking cessation rates after 12 months of follow up stratified by baseline spirometric results

\begin{tabular}{|c|c|c|c|c|c|}
\hline \multirow[b]{2}{*}{ Spirometric results } & \multirow[b]{2}{*}{ Normal } & \multicolumn{4}{|c|}{ Airway obstruction } \\
\hline & & Mild & Moderate & Severe & Any \\
\hline All subjects (n) & 3441 & 384 & 939 & 357 & 1680 \\
\hline Quitters (n) & 413 & 56 & 151 & 66 & 273 \\
\hline Cessation rate (\%) & $12.0 \%$ & $14.6 \%$ & $16.1 \%$ & $18.5 \%$ & $16.3 \%$ \\
\hline$p$ value* & - & 0.229 & 0.005 & 0.003 & 0.0003 \\
\hline
\end{tabular}

We used spirometric results to demonstrate the harmful effects of smoking and to reinforce smoking cessation advice. A similar type of intervention was applied in another study where CO levels in the exhaled air were used to show smokers how much of the lethal gas they had accumulated in their bodies. Two hundred and ten smokers were randomly allocated to four groups: control (no intervention) group, smoking cessation advice group, smoking cessation advice + CO measurements in the exhaled air group, and smoking cessation advice + offer of further help group. After 1 year the highest smoking cessation rate $(17 \%)$ was observed in the exhaled CO group, compared with $15 \%$ in the smoking cessation advice group, $13 \%$ in the smoking cessation advice + further help group, and $11 \%$ in the control group. ${ }^{22}$

Smoking cessation intervention combined with spirometry was applied in the first Lung Health Study in a large cohort of subjects with mild to moderate airway obstruction. ${ }^{8}$ Behavioural techniques and nicotine replacement therapy during the first 6 months for the intensive intervention group resulted in a biochemically verified smoking cessation rate of $22 \%$ during 5 years of follow up. The 1 year cessation rate in this group was $35 \%$. In comparison, the 5 year sustained cessation rate was only $5 \%$ in the usual care group in the First Lung Health Study; 93\% of those who had quit for 5 years remained non-smokers after a total of 11 years of follow up. ${ }^{23}$

Other studies of the benefits of combining smoking cessation advice with spirometry have reported much lower cessation rates. A letter with advice to stop smoking sent to workers with workplace exposure to asbestos and low lung function resulted in a smoking cessation rate of 5.6\% at 1 year which was significantly different from the 3.5\% cessation rate in those who did not receive the letter. ${ }^{24}$

In another study, smoking cessation advice combined with spirometry resulted in a smoking cessation rate of $6.5 \%$ which was not significantly different from the $4.5 \%$ sustained (12 months) and validated (cotinine in urine) cessation rate in smokers who received only smoking cessation counselling or only minimal smoking cessation intervention. ${ }^{25}$ Badgett and Tanaka ${ }^{26}$ and a new report from the Agency for Healthcare Research and Quality ${ }^{27}$ have expressed doubts that spirometry substantially enhances smoking cessation rates when added to traditional techniques such as physician advice, nicotine replacement therapy, or counselling. However, a consensus statement from the United States National Lung Health Education Program (NLHEP) recommended spirometric testing to increase the motivation of smokers to quit. ${ }^{28}$ Our results help to confirm this. We believe that the results of objective spirometric measurements superimposed on a simplified diagram of $\mathrm{FEV}_{1}$ decline in non-smokers versus COPD patients was taken very seriously by the middle aged smokers attending our Program. This may explain the higher smoking cessation rate in our study compared with general practitioner's advice. ${ }^{17-19}$

In contrast to our findings, the Lung Health Study found that smokers with moderate airway obstruction were not more likely than those with borderline to mild airway obstruction to quit smoking..$^{29}$ This difference may be because the Lung Health Study excluded smokers with normal lung function, so their power to show a difference was much lower than in our study, which included over 2000 smokers with normal spirometric values.

Our smoking cessation rates would probably have been even higher if we had been able to offer nicotine replacement therapy $^{30}{ }^{31}$ or bupropion ${ }^{29} 323$ for several months at no cost to our study participants.

Molyneux et $a l^{30}$ compared the effects of nicotine replacement therapy, brief counselling, and minimal intervention in 274 smokers. Interventions were performed during hospitalisation. At 12 months, the smoking cessation rate was significantly higher in the group receiving nicotine replacement therapy plus brief counselling than in the group given brief counselling alone $(17 \% \vee 6 \%)$. Short term positive effects of nicotine replacement therapy plus counselling-but not at 6 or 12 months-were recently reported by Hand et al. ${ }^{34}$

Smoking cessation in patients with COPD is of paramount importance. Despite continuation of airway inflammation in COPD ex-smokers, ${ }^{35}$ the mean annual decline in $\mathrm{FEV}_{1}$ returns to that observed in healthy non-smokers. ${ }^{23}$ There is also a definitive reduction in the death rate from lung cancer, myocardial infarction, and stroke in sustained non-smokers compared with continuing smokers. ${ }^{36}{ }^{37}$

The number of previous cessation attempts (approximately two) characterising the population in our study was rather low. The mean number of cessation attempts in sustained

Table 4 Influence of age, sex, number of cigarettes smoked daily, nicotine dependence, and airflow obstruction in logistic regression model assessing sustained 1 year smoking cessation

\begin{tabular}{lllll}
\hline Variable & $\boldsymbol{\beta}$ & OR & $\mathbf{9 5 \%} \mathbf{C l}$ & p value \\
\hline Age & 0.0062 & 1.0062 & 0.99 to 1.02 & 0.22 \\
No of cigarettes smoked daily & -0.0180 & 0.9822 & 0.96 to 1.00 & 0.04 \\
FTND & -0.1331 & 0.8754 & 0.83 to 0.92 & 0.0001 \\
Airflow obstruction & 0.4402 & 1.5529 & 1.24 to 1.95 & 0.0002 \\
Female sex & -0.1562 & 0.8554 & 0.69 to 1.06 & 0.15 \\
\hline
\end{tabular}

FTND, Fagerström test for nicotine dependence; $\mathrm{OR}$, odds ratio, $\operatorname{Exp}(\beta)$; $\mathrm{Cl}$, confidence interval. 
ex-smokers in Poland is seven. ${ }^{38}$ Our Program probably attracted smokers who had not previously been encouraged by their general practitioners to quit.

Our study has limitations. The subjects were all volunteers from Poland and thus may not be representative of all smokers in other countries. They also showed an interest in their own health by presenting themselves to the Program, and thus were probably more motivated to quit than other smokers. Our follow up rate was $68 \%$, but our primary findings were unchanged when we conservatively assumed that all non-responders were continuing smokers. The very limited data available on the "background quit rate" in Poland (The Great Polish Smoke-out) showed that it was very low. Since we did not randomise the study participants to spirometry versus no spirometry, unmeasured confounders may have caused the association of abnormal spirometric values with better smoking cessation rates. A large randomised clinical trial is needed to answer this important question more conclusively.

In summary, we have shown that spirometry combined with short smoking cessation advice from a physician resulted in relatively high smoking cessation rates in adult smokers. Smokers with airflow limitation had significantly higher smoking cessation rate than smokers with normal spirometry. Screening of adult smokers to detect airway obstruction using spirometric tests performed by trained technologists, combined with strong smoking cessation advice, has the potential to reduce the burden of COPD in entire countries.

\section{ACKNOWLEDGEMENTS}

The authors thank Katarzyna Szamotulska of the Institute of Mother and Child in Warsaw for help with statistical analysis.

\section{Authors' affiliations}

M Bednarek, D Gorecka, J Zielinski, 2nd Department of Respiratory Medicine, National Research Institute of Tuberculosis and Lung Diseases, Warsaw, Poland

J Wielgomas, Outpatient Chest Clinic, Wloclawek, Poland M Czajkowska-Malinowska, Outpatient Chest Clinic, Bydgoszcz, Poland

J Regula, Outpatient Chest Clinic, Dzialdowo, Poland

G Mieszko-Filipczyk, Outpatient Chest Clinic, Byłom, Poland

M Jasionowicz, Outpatient Chest Clinic, Lublin, Poland

R Bijata-Bronisz, Outpatient Chest Clinic, Inowroclaw, Poland

M Lempicka-Jastrzebska, Outpatient Chest Clinic, Warsaw (Ochota), Poland

M Czajkowski, Outpatient Chest Clinic, Warsaw (Saska Kepa), Poland G Przybylski, Outpatient Chest Clinic, Swiecie, Poland

Supported by Polish State Committee for Scientific Research grant no. 6 PO5D 02921.

Competing interests: none declared.

\section{REFERENCES}

1 Pauwels RA, Buist AS, Calverley PM, et al. Global strategy for the diagnosis, management, and prevention of chronic obstructive pulmonary disease. NHLBI/WHO Global Initiative for Chronic Obstructive Lung Disease (GOLD) Workshop summary. Am J Respir Crit Care Med 2001;163:1256-76.

2 National Center for Health Statistics. Vital Health Stat Series 1998; 10:193.

3 Sullivan SD, Ramsey SD, Lee TA. The economic burden of COPD. Chest 2000;117(Suppl 2):5-9S.

4 Sin DD, Stafinski T, Ng YC, et al. The impact of chronic obstructive pulmonary disease on work loss in the United States. Am J Respir Crit Care Med 2002; 165:704-7

5 Murray RP, Anthonisen NR, Connett JE, et al. Effects of multiple attempts to quit smoking and relapses to smoking on pulmonary function. Lung Health Study Research Group. J Clin Epidemiol 1998;51:1317-26.

6 Burrows B, Knudson RJ, Cline MG, et al. Quantitative relationships between cigarette smoking and ventilatory function. Am Rev Respir Dis 1977; 115:195-205.

7 Lange P, Groth S, Nyboe GJ, et al. Effects of smoking and changes in smoking habits on the decline of $\mathrm{FEV}_{1}$. Eur Respir J 1989;2:811-6.
8 Anthonisen NR, Connett JE, Kiley JP, et al. Effects of smoking intervention and the use of an inhaled anticholinergic bronchodilator on the rate of decline of $\mathrm{FEV}_{1}$. The Lung Health Study. JAMA 1994;272:1497-505.

9 Burchfiel CM, Marcus EB, Curb JD, et al. Effects of smoking and smoking cessation on longitudinal decline in pulmonary function. Am J Respir Crit Care Med 1995;151:1778-85.

10 van Schayck CP, Loozen JMC, Wagena E, et al. Detecting patients at high risk of developing chronic obstructive pulmonary disease in general practice: cross sectional case finding study. BMJ 2002;324:1370-5.

11 Zielinski J, Bednarek M, Gorecka D, et al. Increasing COPD awareness. Early detection of COPD by high-risk population screening. Eur Respir J 2006;27:833-52.

12 American Thoracic Society. Standardization of spirometry, 1994 update. Am J Respir Crit Care Med 1995;152:1107-36.

13 Quanjer PH, Tammeling GJ, Cotes JE, et al. Lung volumes and forced ventilatory flows. Report Working Party Standardization of Lung Function Tests, European Community for Steel and Coal. Official Statement of the European Respiratory Society. Eur Respir J Suppl 1993;16:5-40.

14 Siafakas NM, Vermeire P, Pride NB, et al. Optimal assessment and management of chronic obstructive pulmonary disease (COPD). The European Respiratory Society Task Force. Eur Respir J 1995;8:1398-420.

15 Fletcher CM, Peto R. The natural history of chronic airflow obstruction. BMJ 1977;1:1645-8.

16 Heatherton TF, Kozlowski LT, Frecker RC, et al. The Fagerstrom Test for Nicotine Dependence: a revision of the Fagerstrom Tolerance Questionnaire. Br J Addict 1991;86:1119-27.

17 Gilpin EA, Pierce JP, Johnson $M$, et al. Physician advice to quit smoking: results from the 1990 California Tobacco Survey. J Gen Intern Med 1993;8:549-53.

18 Russell MA, Wilson C, Taylor C, et al. Effect of general practitioners' advice against smoking. BMJ 1979;2:231-5.

19 Silagy C, Stead LF. Physician advice for smoking cessation. Cochrane Database Syst Rev, 2001;CD000165..

20 Subcommittee of the Research Committee of the British Thoracic Society Comparison of four methods of smoking withdrawal in patients with smoking related diseases. BMJ 1983;286:595-7.

21 Subcommittee of the Research Committee of the British Thoracic Society Smoking withdrawal in hospital patients: factors associated with outcome. Thorax 1984;39:651-6.

22 Jamrozik K, Vessey M, Fowler G, et al. Controlled trial of three different antismoking interventions in general practice. BMJ 1984:288:1499-503.

23 Anthonisen NR, Connett JE, Murray RP. Smoking and lung function of Lung Health Study participants after 11 years. Am J Respir Crit Care Med 2002; 166:675-9

24 Humerfelt S, Eide GE, Kvale G, et al. Effectiveness of postal smoking cessation advice: a randomized controlled trial in young men with reduced $\mathrm{FEV}_{1}$ and asbestos exposure. Eur Respir J 1998;11:284-90.

25 Segnan N, Ponti A, Battista RN, et al. A randomized trial of smoking cessation interventions in general practice in Italy. Cancer Causes Control $1991 ; 2: 239-46$.

26 Badgett RG, Tanaka DJ. Is screening for chronic obstructive pulmonary disease justified? Prev Med 1997;26:466-72.

27 Agency for Healthcare Research and Quality. Use of spirometry for case finding, diagnosis, and management of chronic obstructive pulmonary disease (COPD), AHRQ Publication No.05-E017-2, 2005.www.ahrq.gov/ downloads/pub/evidence/pdf/spirocopd/spiro.pdf /accessed 10 April 2006).

28 Ferguson GT, Enright PL, Buist AS, et al. Office spirometry for lung health assessment in adults: a consensus statement from the National Lung Health Education Program. Chest 2000;117:1146-61.

29 Murray RP, Gerald LB, Lindgren PG, et al. Characteristics of participants who stop smoking and sustain abstinence for 1 and 5 years in the Lung Health Study. Prev Med 2000;30:392-400.

30 Molyneux A, Lewis S, Leivers U, et al. Clinical trial comparing nicotine replacement therapy (NRT) plus brief counselling, brief counselling alone, and minimal intervention on smoking cessation in hospital inpatients. Thorax 2003;58:484-8.

31 Tonnesen P, Paoletti P, Gustavsson G, et al. Higher dosage nicotine patches increase one-year smoking cessation rates: results from the European CEASE trial. Collaborative European Anti-Smoking Evaluation. European Respiratory Society. Eur Respir J 1999;13:238-46.

32 Hurt RD, Sachs DP, Glover ED, et al. A comparison of sustained-release bupropion and placebo for smoking cessation. N Engl J Med 1997;337:1195-202.

33 Jorenby DE, Leischow SJ, Nides MA, et al. A controlled trial of sustainedrelease bupropion, a nicotine patch, or both for smoking cessation. N Engl J Med 1999;340:685-91.

34 Hand S, Edwards S, Campbell IA, et al. Controlled trial of three weeks nicotine replacement treatment in hospital patients also given advice and support. Thorax 2002;57:715-8.

35 Rutgers SR, Postma DS, ten Hacken $\mathrm{NH}$, et al. Ongoing airway inflammation in patients with COPD who do not currently smoke. Thorax 2000;55:12-8.

36 Pelkonen $M$, Tukiainen $\mathrm{H}$, Tervahauta $\mathrm{M}$, et al. Pulmonary function, smoking cessation and 30 year mortality in middle aged Finnish men. Thorax 2000:55:746-50.

37 Anthonisen NR. Smoking, lung function, and mortality. Thorax 2000;55:729-30.

38 Zatonski W. Tobacco smoking in Central European countries: Poland. In: Boyle P, Gray N, Henningfield J, et al. Tobacco and public health: science and policy. Oxford: Oxford University Press, 2004:235-52. 